\title{
SÍNDROME DE COCKAYNE
}

\author{
RELATO DE CASO
}

\author{
ANA GUARDIOLA*, CLÉBER RIBEIRO ÁLVARES-DA-SILVA**, \\ JOSÉ RENATO GUIMARÃES GRISOLIA***, ROGÉRIO SILBERMANN****
}

\begin{abstract}
RESUMO - Apresenta-se um caso de síndrome de Cockayne, definem-se os critérios diagnósticos e identificamse as complicações desta síndrome. Os critérios para diagnóstico deste quadro são: crescimento pobre, observado desde a vida intra-uterina, anormalidades neurológicas (desde o nascimento), perda auditiva neurossensorial, catarata (aparecimento nos primeiros 3 anos), anomalias estruturais congênitas do olho, retinopatia pigmentosa, fotossensibilidade cutânea, cáries dentárias, vida média de 12-13 anos (pode chegar aos 20 anos). O largo espectro de sintomas e sua severidade indicam distúrbio bioquímico e genético raro, de herança autossômica recessiva.
\end{abstract}

PALAVRAS-CHAVE: síndrome de Cockayne, retardo de desenvolvimento, herança autossômica recessiva, microcefalia.

\section{Cockayne syndrome: case report}

ABSTRACT - We describe a girl with Cockayne syndrome (CS), the diagnostic criteria and the complications of this syndrome. The required criteria for the diagnosis include: prenatal poor growth failure, congenital structural eye anomalies, cataracts, pigmentary retinopathy, severe neurologic dysfunction from birth, sensorineural hearing loss, cutaneous photosensitivity and dental caries. CS is a rare autosomal recessive and biochemical disorder.

KEY WORDS: Cockayne syndrome, developmental delay, autosomal recessive inheritance, microcephaly.

A síndrome de Cockayne é um distúrbio raro, autossômico recessivo, de patogênese desconhecida com prejuízo no crescimento e disfunção progressiva neurológica. Cockayne em 1936 descreveu esta entidade na observação de duas crianças com nanismo, atrofia e surdez ${ }^{1}$.

Moossy ${ }^{2}$ fazendo uma revisão desta síndrome salienta que as características mais importantes são: 1) gestação e parto sem particularidades; 2) peso de nascimento normal; 3) dermatite por fotossensibilidade que começa em torno dos 6 meses de idade; 4) retardo de crescimento com nanismo e cifose; 5) alterações neurológicas como microcefalia, retardo mental, retinite pigmentosa, atrofia óptica e sinais de comprometimento do neurônio motor superior e do cerebelo de progressão lenta; 6) aspecto característico do rosto com nariz em bico de "papagaio" e dermatite seborréica na face em forma de asa de borboleta; 7) deterioração progressiva com cegueira, surdez e morte por inanição e complicações infecciosas na adolescência ou na terceira década de vida como máximo; 8) dados genéticos compatíveis com herança autossômica recessiva. Esta entidade tem se associado a diversos transtornos, como hiperbetalipoproteinemia, hiperinsulinemia, nefropatia e níveis baixos de glicose no sangue, anormalidades na regulação da glicose sanguinea, neuropatia periférica com diminuição da velocidade de condução nervosa e desmielinização segmentar ${ }^{3-5}$.

*Professora Adjunta do Departamento de Neurologia da Fundação Faculdade Federal de Ciências Médicas de Porto Alegre (FFFCMPA); **Professor Adjunto do Departamento de Neurologia da FFFCMPA,; ***Residente de Neurologia da FFFCMPA; ****Residente de Genética Médica da FFFCMPA. Aceite: 30-outubro-1998.

Dra. Ana Guardiola - Rua Sarmento Leite 245 - 90050-170 Porto Alegre RS - Brasil. 
O propósito de apresentar este relato é chamar a atenção para essa entidade rara, hereditária, que cursa com alterações neurológicas, oculares, dermatológicas e odontológicas, evoluindo com deterioração progressiva e inexoravelmente para morte.

\section{RELATO DE CASO}

DS, 3 anos e 10 meses, feminina, branca, natural e procedente de Eldorado do Sul (Figs 1 e 2), que consulta por retardo de desenvolvimento. Nos antecedentes gineco-obstétricos destaca-se que a mãe é Gesta 8 Para 6 Aborto 1 natimorto1, sendo esta a $7^{\mathrm{a}}$ gestação (1 aborto e 1 natimorto prévios), parto domiciliar e sem atendimento pré-natal, peso ao nascimento $3030 \mathrm{~g}$. Na revisão de sistemas foi referida cabeça pequena (não tem certeza se já tinha esta característica ao nascimento), alergia na face quando é exposta ao sol, cáries nos dentes e retardo no crescimento. Firmou a cabeça com 5 meses, sentou com apoio com 8 meses, sentou sem apoio aos 12 meses, engatinhou aos 16 meses, ficou em pé aos 18 meses, primeiras palavras aos 18 meses, dissílabas aos 24 meses. Tem história de hepatite com 1 mês e meio de vida, internada em hospital para avaliação e tratamento (realizou exames: IgM positivo para citomegalovírus e ecografia abdominal mostrando esplenomegalia). Seus são pais consanguíneos, tem 3 irmãos homens (18 anos, 10 anos e 2 anos), 2 irmãs mulheres (17 anos e 16 anos) normais, não havendo história familiar semelhante na família.

No exame físico geral constata-se regular estado geral, mucosas úmidas e coradas, acianótica, anictérica, afebril, eupnéica, sinais vitais estáveis, retardo de crescimento (peso $8250 \mathrm{~g} /$ estatura $78 \mathrm{~cm}$ ), microcefalia visível, vários dentes sépticos, micrognatia, clinodactilia do $5^{\circ}$ dedo da mão esquerda, lesão hiperemiada e crostosa extensa na face.

Exame neurológico - Psiquismo: contactua pobre e inadequadamente com o examinador. Crânio: perímetro cefálico $39 \mathrm{~cm}$, distância anteroposterior $22,5 \mathrm{~cm}$, distância biauricular $21 \mathrm{~cm}$, fontanelas fechadas. Fácies: aspecto de "pássaro". Atitude: deitada em decúbito dorsal com os quatro membros em extensão (membros inferiores com sinal de Little). Emissão de sons: choro/lalação. Movimentação voluntária: escassa. Movimentação involuntária: ausente. Tonos: hipertonia elástica dos quatro membros. Reflexos miotáticos fásicos: hiperreflexia global simétrica. Reflexos superficiais: cutâneoplantar esquerdo indiferente e direito em flexão, cutâneo-abdominais ausentes. Força: tetraparesia grau IV. Sensibilidade: álgica e vibratória presentes. Reflexos arcaicos: ausentes. Nervos cranianos: fotomotor presente, oculocefálico ausente. Fundo de olho com papilas pálidas e retinopatia pigmentar. Trofismo da pele e muscular: hipotrofia muscular generalizada

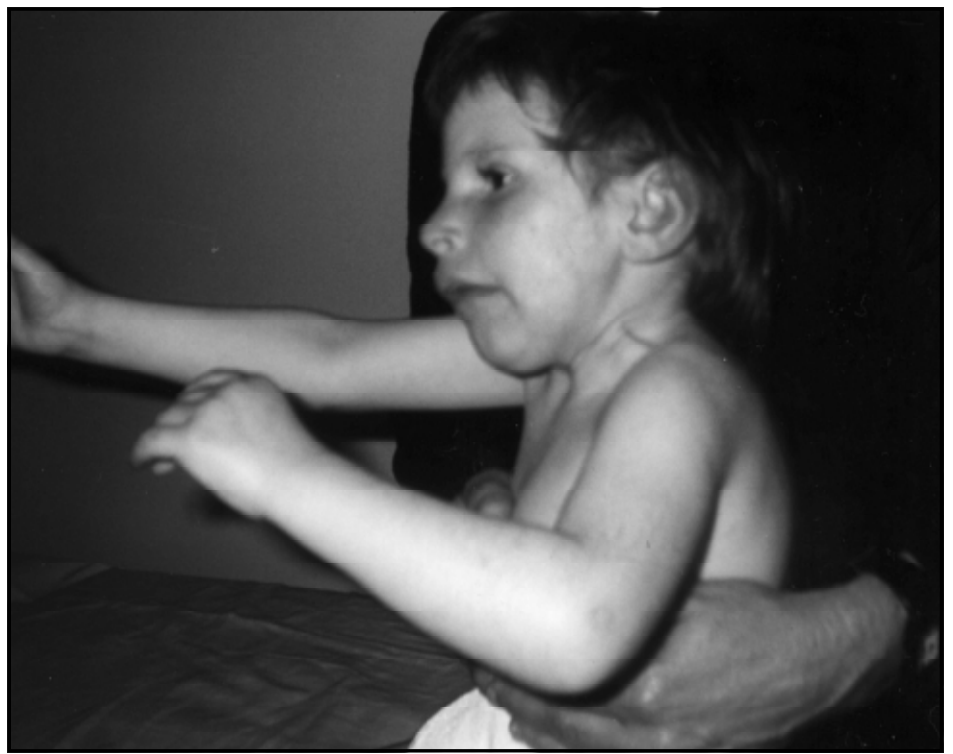

Fig 1. Síndrome de Cockayne: paciente relatada 


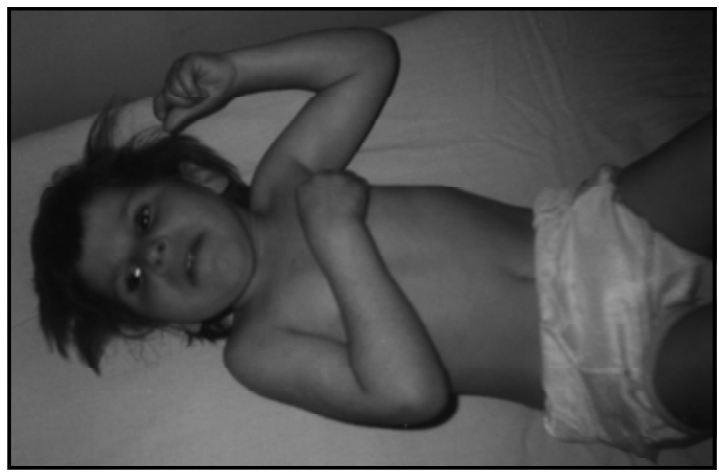

Fig 2. Síndrome de Cockayne: paciente relatada

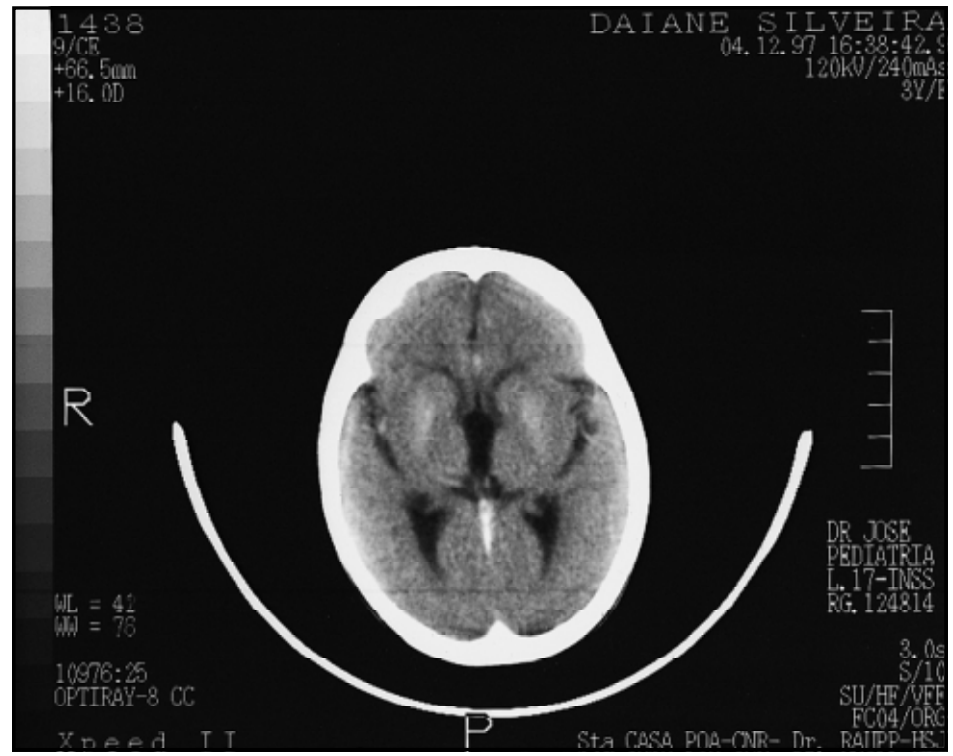

Fig 3. Paciente relatada. TC. Espaço subaracnóideo aumentado, dilatação ventricular ex-vácuo e hiperdensidade bilateral em topografia de núcleos da base.

Desenvolvimento neuropsicomotor - Postura: mantém-se sentada sem apoio durante um período curto; deitada em decúbito ventral, desfaz-se do pano colocado na sua cabeça. Coordenação visomanual: segue com o olhar uma pessoa que se desloca no quarto; segue um objeto num ângulo de $180^{\circ}$; mantém firmemente o chocalho e o sacode com movimentos bruscos. Linguagem: emite algumas vocalizações. Sociabilidade: imobiliza-se ou fica quieta quando se lhe fala, sorri aos rostos familiares.

Investigação - STORCH: negativo. Anti-HIV: negativo. Alteração de função hepática com aumento de transaminases (TGO, TGP) e desidrogenase lática (DHL). Marcadores para hepatite negativos (A, B e C). Ecografia abdominal: esplenomegalia. Raio X de crânio: microcefalia. Tomografia computadorizada do crânio (TC): espaço subaracnóideo aumentado, dilatação ventricular ex-vácuo, hiperdensidade bilateral em topografia de núcleos da base (Fig 3). Avaliação oftalmológica: microftalmia, papilas pálidas bilateral em ambos olhos com embainhamento dos vasos, principalmente no olho esquerdo, retina pálida e com padrão salpicado acinzentado (sal e pimenta); exame oftalmológico compatível com síndrome de Cockayne. Avaliação genética: quadro clínico compatível com síndrome de Cockayne. 
Quadro 1. Manifestações Neurológicas na SC.

Retardo no desenvolvimento neuropsíquico e cognitivo com deterioração nas funções neuropsicológicas

Alteração da motricidade: fraqueza, atrofia muscular, movimentos anormais (tremor, mioclonias), distúrbios de tono (predominantemente hipertonia, podendo haver hipotonia), alteração dos reflexos, alteração na função cerebelar, paresias ou plegias

Convulsões

Cefaléia

Quadro 2. Manifestações oftalmológicas na SC.

Diminuição da lacrimação

Infiltrados corneanos com opacidades ou queratopatia em banda

Catarata

Pupilas mióticas

Atrofia ou hipoplasia óptica

Vasos retinianos estreitos

Retinopatia pigmentosa

Hemorragia retiniana

Coriorretinite

Hiperopia

Presbiopia

Estrabismo

Nistagmo

Fotofobia

Microcórnea

Úlcera corneana

Dacrocistite crônica

Cisto epidérmico e pálpebra

Microftalmia

Hipoplasia da íris

Quadro 3. Manifestações otorrinolaringológicas na SC.

Diminuição da audição

Atrofia da mucosa nasal

Amígdalas hipotróficas ou hiperplásicas

Fenda palatina
Quadro 4. Anormalidades dentárias na SC.

\section{Cáries}

Retardo da erupção dentária

Má oclusão

Dentes hipoplásicos ou ausentes

\section{DISCUSSÃO}

Cantani e cols ${ }^{6}$ fazem revisão em 129 casos relatados na literatura e Nance e Berry ${ }^{7}$ apresentam 5 pacientes por eles diagnosticados e 135 casos da literatura, definindo as características clínicas, discutem casos atípicos e comentam a importância dos ensaios bioquímicos do metabolismo do ácido nucléico, ajudando na definição deste quadro.

Os Quadros 1,2, 3 e 4 mostram as manifestações neurológicas, oftalmológicas, otorrinolaringológicas e dentárias observadas na SC.

A avaliação do paciente com suspeita de SC inclui cuidadosa história e detalhado exame físico focalizando particularmente as áreas neurológica, oftalmológica, cutânea e odontológica ${ }^{8}$. Devem ser feitos exames que confirmem ou não a disfunção do sistema nervoso central (substância branca) e periférico: TC e ressonância magnética do encéfalo, potenciais evocados auditivo e visual, pesquisa de erros inatos do metabolismo e líquor.

A análise da sensibilidade dos fibroblastos à luz ultravioleta em combinação com estudos do metabolismo do DNA representa o teste específico no diagnóstico da $\mathrm{SC}^{7}$. Também pode-se realizar diagnóstico pela medida da síntese de RNA após a irradiação com ultravioleta9 . 
O manejo da SC é puramente sintomático, não existe restrição na dieta, nem tratamento farmacológico. Preconiza-se avaliação periódica, fisioterapia para prevenir contraturas e manter a deambulação, aconselha-se a não exposição solar.

Impõe-se avaliação e aconselhamento genético nas famílias de portadores desta afecção, a fim de prevenir o nascimento de mais acometidos.

Nosso caso apresentava as características clínicas neurológicas, oftalmológicas, dermatológicas e odontológicas da síndrome de Cockayne. Na TC, observou-se atrofia cortical e hiperdensidade dos núcleos da base e o raio X simples de crânio mostrou microcefalia. As provas de função hepática (TGO, TGP e DHL) mostraram alterações. A avaliação laboratorial para hepatite foi negativa observação comentada na literatura ${ }^{7}$.

\section{REFERÊNCIAS}

1. Cockayne EA. Dwarfism with retinal atrophy and deafness. Arch Dis Child 1936;11:1-8.

2. Moossy J. The neuropathology of Cockayne's syndrome. J Neuropathol Exp Neurol 1967;26:654-660.

3. Fujimoto WY, Greene ML, Seegmiller JE. Cockayne's syndrome: report of a case with hyperlipoproteinemia, hyperinsulinemia, renal disease, and abnormal growth hormone. J Pediatr 1969;75:881-884.

4. Cotton RB, Keats TE, McCoy EE. Abnormal blood glucose regulation in Cockayne's syndrome. Pediatrics 1970;46:54-60.

5. Moosa A, Dubowitz V. Peripheral neuropathy in Cockayne's syndrome. Arch Dis Child 1970;45:674-677.

6. Cantani A, Bamonte G, Belioni P, Tucci Bamonte M, Ceccoli D, Tacconi ML. Cockayne syndrome: a review of 129 cases so far reported in the literature. Eur Rev Med Pharm Sci 1987;9:9-17.

7. Nance MA, Berry SA. Cockayne syndrome: review of 140 cases. Am J Med Genet 1992;42:68-84.

8. Jones KL. Smith's recognizable patterns of human malformation. 5Ed. Philadelphia: W. B. Saunders 1997:144-147.

9. Lehmann AR, Thompson AF, Harcourt SA, Stefanini M, Norris PG. Cockayne's syndrome: correlation of clinical features with cellular sensitivity of RNA synthesis to UV irradiation. J Med Genet 1993;30:679-682. 